\title{
MINOR RURAL BUILDING HERITAGE AND TERRITORIAL FEATURES IN LOCAL ACTION GROUP SUD EST BARESE AREA (SOUTHERN ITALY)
}

\author{
Marco Parlavecchia, Simone Pascuzzi, Francesco Santoro, Giuseppe Ruggiero \\ University of Bari Aldo Moro, Italy \\ giuseppe.ruggiero@uniba.it
}

\begin{abstract}
In Apulia, minor rural buildings are normally affected by intense forms of abandonment and decay. These minor constructions are often reused in ways that are not in line with both their own characteristics and the territorial context that encloses them. These forms of deterioration often lead to disappearance of this heritage. This study is focused on the analysis of the minor rural building heritage and its relationship with the actual territory context of the Local Action Group Sud Est Barese (LAG SEB), made up of nine municipalities. The official cartography of Military Geographic Institute (IGM, 1:25 000), the Regional Technical Map (CTR, 1:5 000), the Informative Territorial System (SIT Puglia) database, and the Geographic Information System (GIS) software ArcMap ArcGis 10.5 were used in order to constitute the base cartography. To obtain information about localization of the rural buildings, IGM cartography has been used due to the greater number of contents related to the classification of buildings. Successively, the overlapping of IGM and CTR map data and the comparison of them with the digital orthophoto were useful to verify whether the buildings listed on IGM cartography still exist. All main territorial features were analyzed using datasets obtained from IGM, CTR and SIT Puglia databases.

This work allowed to investigate the possible relationships between the typology and the distribution of minor rural buildings and the major territorial characteristics, such as land use, road network, orography, and karst formations. It was highlighted that, although all nine municipalities examined fall under the same LAG, these are very different from the point of view of territorial peculiarities and the use and enhancement of resources. Rural buildings in their territorial context near the coast show more diversified potentials, as these areas include different realities (urban centers, tourist and seasonal residential areas, production areas, etc.), while the innermost buildings are located in municipalities with a predominantly productive destination. The obtained results represent useful information to outline intervention policies, the implementation of which would serve to attempt to recover the building structures, or improve the quality and way of using them.
\end{abstract}

Keywords: rural buildings, territory, heritage, cartography, Apulia.

\section{Introduction}

In the southern Italy, Apulian rich and varied rural building heritage is often inadequately maintained. In some extreme cases, constructions have been destroyed. Principally, this degradation comes from two evolutionary aspects of the territorial matrix: the urban expansion, which causes the incorporation of the rural landscape, and the structural changes of modern agriculture. Therefore, the preliminary knowledge of the characteristics of historic rural buildings and of the changed territory that includes them is essential in order to implement policies to enhance this heritage [1]. Because of their greater potential for recovery and re-use and their greater diffusion in the territory, most of the studies focused on rural buildings refer to farmhouses [2]. The minor rural architecture has always been ignored despite the high diffusion and the historical value of this type of construction. Often the smaller buildings are neglected or reused in improper ways, without taking into account the territorial context that surrounds them. Sometimes they are demolished without taking into account the cultural heritage they constitute. Therefore, more attention must be paid to their conservation. Recent research has aimed to identify minor rural architecture in the changed territorial contexts, essential for the protection of spatial planning and redevelopment interventions [3-5].

The recent development policies applied by European states attest the close relationship between rural heritage and the surrounding lands [6]. Rural heritage and cultural landscape are the identity card of local places and cultures [7]. Thus, a strong relationship is recognized between historic rural constructions and the territorial context [1;8-9]. Apulian rural buildings are varied, depending on the area and the agro-zootechnical sector to which they belong, and on the materials which were used to build them. Often, the original location of each building was related to the intended use or, sometimes and for some construction types, to the need for a seasonal dwelling. Considering today's changed territorial features, it is necessary to promote a respectful renewal of buildings, in order to safeguard and preserve the territorial heritage for future generations [10-12]. On the other hand, the recent expansion of rural tourism registered in Europe [13] and in particular in Apulia [14-15], makes it indispensable, even to redevelop it, in a perspective of sustainable tourism planning [16]. Nowadays, in Italy the 
protection policies related to the rural heritage are developed by the regions. With resolution No. 176 of 2015, the Regional Territorial Landscape Plan (PPTR) was approved. It includes guidelines for the recovery, maintenance and reuse of constructions and rural assets, as well as guidelines for the protection, restoration and interventions on dry stone buildings and manufactures [17]. The conservation of rural buildings is among the priorities of the European Union' rural development policies [11; 18]. In recent years, Local Action Groups (LAGs) have coordinated local territorial planning as part of the EU initiative called the Liaison Entre Actions de Développement de l'Économie Rurale (LEADER). The initiative promotes sustainable development of rural areas in the EU. The importance of historic rural buildings was also recognized by a regional territorial planning policy through the Regional Territorial Landscape Plan (PPTR) (Resolution No. 176 of 2015), which includes guidelines for the recovery, maintenance and reuse of buildings and rural assets as guidelines for the protection, restoration and interventions on buildings and artifacts made of dry stone [17]. Using GIS software it is possible to study the distributional and typological data concerning rural buildings, linking them to various territorial features [19].

Considering the historical and cultural value of the rural heritage spread throughout Apulian territory, this study focuses on identification of the rural buildings and the analysis of the relationship with the most relevant territorial features in the nine municipalities, which compose the LAG SEB, located in the southeast area of the Province of Bari (Apulia, Italy).

\section{Materials and methods}

The official Cartography of the Military Geographic Institute (IGM, elaborated between 1947 and 1958 ) is the richest in toponymic and typological information. Therefore, it was used to identify buildings. In order to exclude the missing buildings from the analysis, the Regional Technique Map updated to 2011 (CTR, ratio in scale 1: 5,000) was used. To validate the results of the cartographic comparison, we used the digital orthophoto with a ground resolution of $50 \mathrm{~cm}$ pixel elaborated in 2016 . These cartographic sources and the website of Sistema Informativo Territoriale Puglia (SIT Puglia) contain also physical and infrastructural data about land use, urban centre and road network, orography, and karst formation. Cartographic processing and data manipulation were carried out using GIS software (ArcMap ArcGis 10.5, Environmental Systems Research Institute, Inc. (ESRI), Redlands, California US-CA).

The local development strategy 2014-2020 of the LAG Sud Est Barese has bet on the attractivity of the territory, even by the consolidation of agro-food supply chain, the enhancement of environmental resources and the development of sustainable tourism. [20]. Therefore, in this context of sustainable territorial development, rural buildings play a fundamental role in the re-qualification activities. Constructions created before the beginning of the Second World War can be considered as historical ones [5]. In this paper, we referred to the main historical building types of the Apulian territory, as defined by IGM cartography and identified by us in previous studies. In the examined territory, the rural heritage includes buildings, different from a typological, dimensional and functional point of view, such as houses and villas, casini, towers, lamie, iazzi (sheep pens) and frantoi (olive mills) $[5 ; 21]$. Historically, in this area, the economy was based on the agricultural sector, with a very important vocation for the production of wine, table grapes, olive oil, cherries, and horticultural plants. Therefore, agriculture and zootechnics have contributed to mold the landscape, shaping a rich rural heritage. The Utilized Agricultural Area (UAA) is approximately $10 \%$ of the entire metropolitan area of Bari. In the area, the communication route network is mostly made up of provincial roads (country roads) and state roads (trunk roads). In particular, there are three provincial roads (S.P. 240, 75, 65), two state roads (S.S. 16 and 100) and one highway (A14) that goes through the Acquaviva delle Fonti territory. This network is integrated by a dense system of rural roads. In this study we took in consideration state roads and provincial roads, which represent the main system useful to reach minor rural buildings. Geologically, the study area $\left(\approx 479 \mathrm{~km}^{2}\right)$ typically consists of limestone and dolomitic rocks and is characterized by the presence of ravines, archaeological sites, caves and karstic sinkhole, such as "doline" and "vore" [20;22].

Rural buildings were preliminarily identified, using IGM cartography (reduction ratio 1:25 000), geo-referencing the constructions named, using GIS software (ArcMap ArcGis 10.5). Subsequently, only minor buildings were considered, excluding the masserie (farmhouses). Then, CTR cartography 
was used in order to remove from the analysis the disappeared buildings. Subsequently, the selected constructions were grouped by type. Finally, the digital orthophoto has allowed us to confirm the disappearance of the missing buildings. To study the connection between the rural buildings and all the territorial components, shape files downloaded from SIT Puglia were used. It was possible to analyze territorial features, like land use, road network and urban centres, orography, and karst formation. The land use shape file, updated in 2011, was obtained from the SIT Puglia website. The overlapping, using ArcMap ArcGIS 10.5, of the rural buildings classified by typology on this layer, has allowed to read the possible links between the features (Fig. 1).

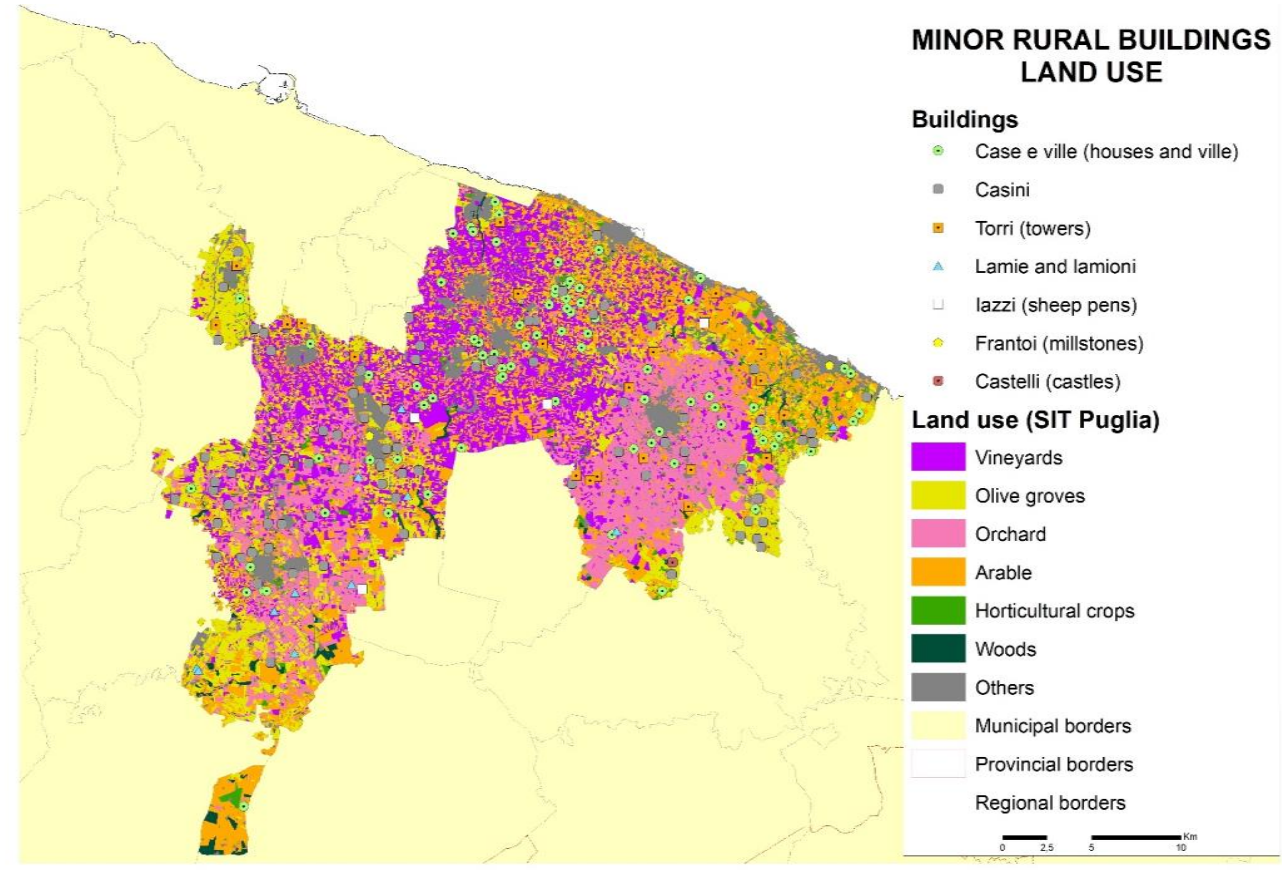

Fig. 1. Minor rural buildings and land use in the study area

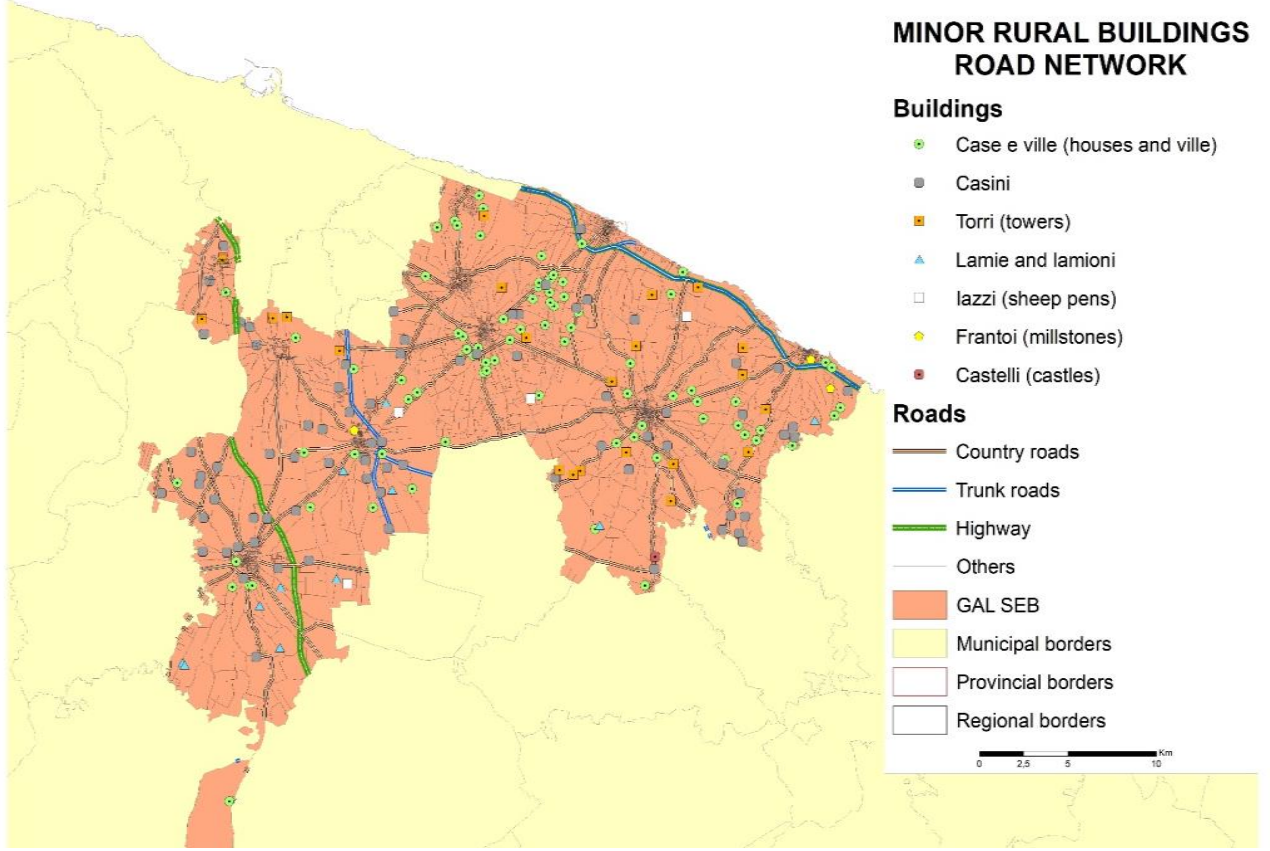

Fig. 2. Minor rural buildings and road network in the study area

To observe the relationship between the buildings, the road network and the urban centres, we proceeded to extract from the CTR an information layer composed of the different categories of roads and the urban centres identified using GIS software. Subsequently, by overlapping the data extracted from the IGM 1: 25000 and from the CTR 1:5 000 the reference map for this part of study was obtained 
(Fig. 2). Successively, using data extracted from the IGM cartography, the relationship between minor rural buildings and the orography of the territory was studied, superimposing the construction map on the contour lines map with equidistances between lines of $25 \mathrm{~m}$ (100 m altimetric bands) (Fig. 3). The karst formation dataset was obtained from the website of SIT Puglia and it was overlapped with the minor rural building map (Fig. 4). In fact, the presence of karst underground formations, such as caves and sinkholes (chasms or dolines), would justify the exploitation of this territory to build underground structures, such as millstones.

Finally, through deep re-reading of the obtained maps it was possible to carry out evaluation of the relationship between the rural building heritage and the territory around it.

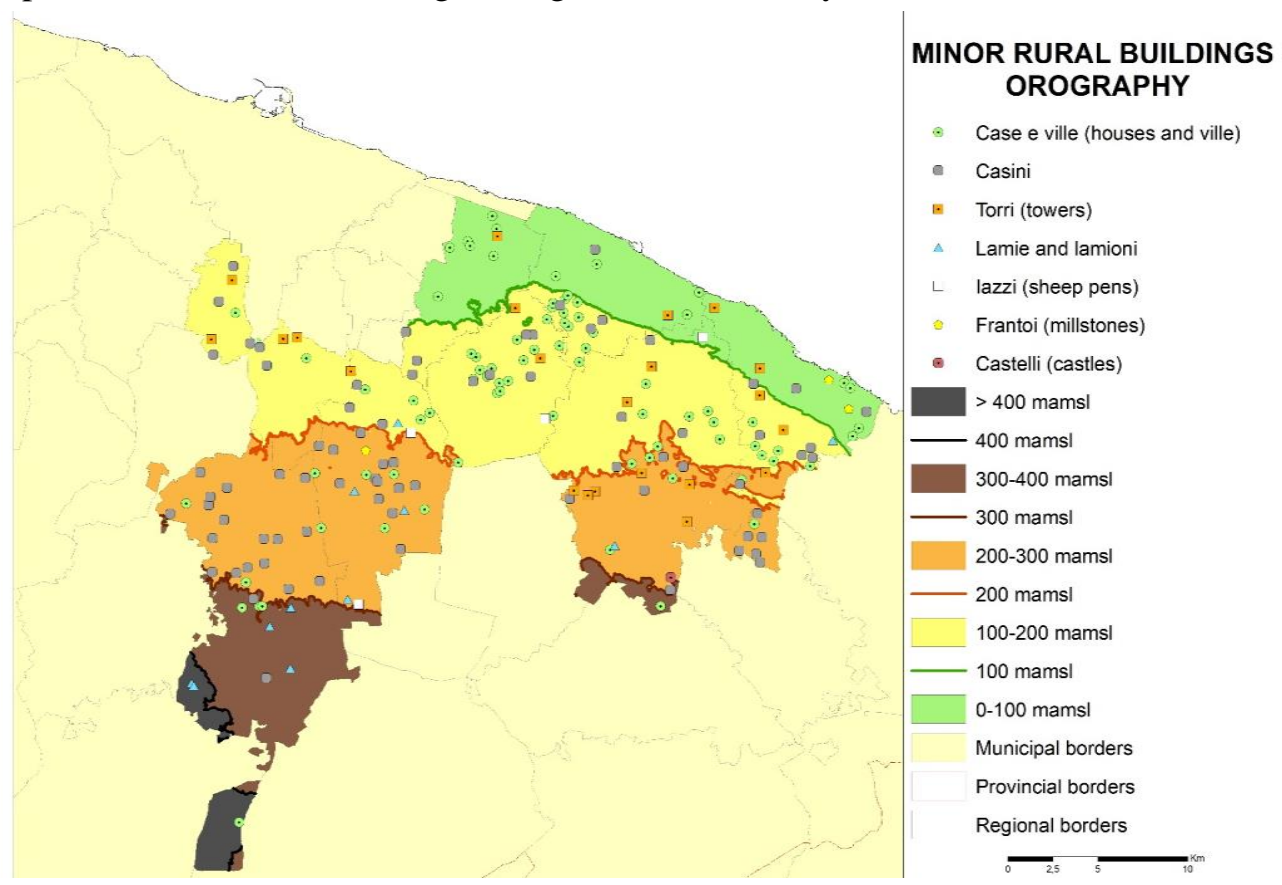

Fig. 3. Minor rural buildings and orography in the study area

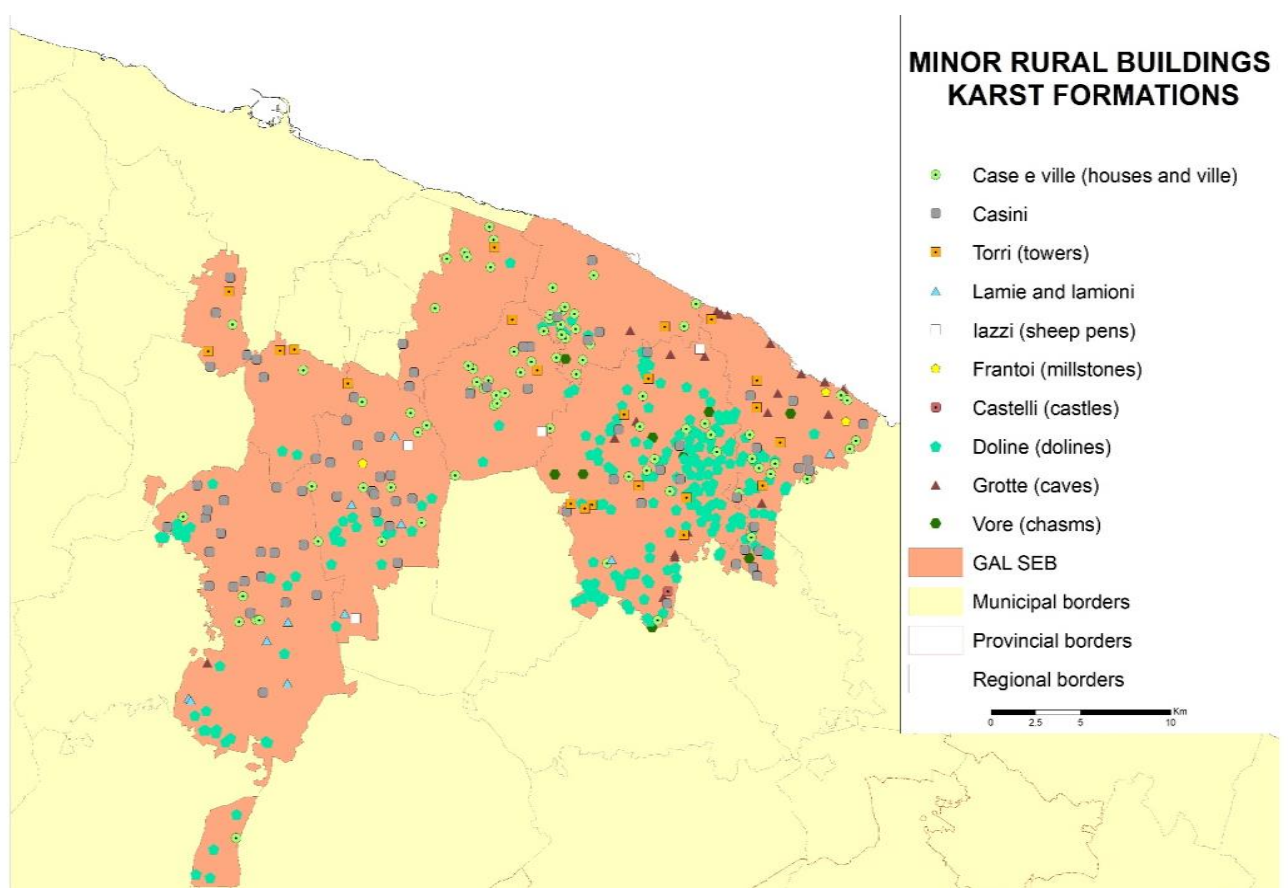

Fig. 4. Minor rural buildings and karst formations in the study area 


\section{Results and discussion}

The first result highlights the numerical representativeness of minor buildings. Out of a total of 495 recorded constructions, $244(49 \%)$ are attributable to minor architectural typologies.From the overlapping of the IGM data to those derived from the CTR, and through the comparison with the orthophoto downloaded from SIT Puglia website, it was also verified that as many as 44 minor constructions disappeared (18\%), confirming the presence of 200 of them, as shown in Table 1.

Table 1

Number and typologies of minor rural buildings in LAG SEB

\begin{tabular}{|c|c|c|c|c|c|c|c|c|c|}
\hline Type & 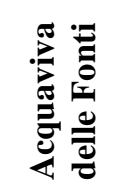 & 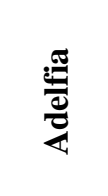 & 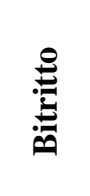 & 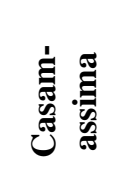 & 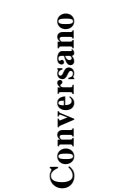 & 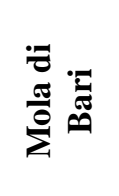 & 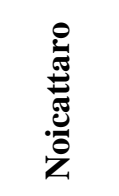 & 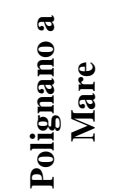 & 兽 \\
\hline Houses and ville & $7(8)$ & $1(1)$ & $1(1)$ & $9(10)$ & $14(16)$ & $16(20)$ & $7(11)$ & $11(11)$ & $16(19)$ \\
\hline Casini & $20(22)$ & $2(3)$ & $4(4)$ & $16(19)$ & $10(12)$ & $4(4)$ & $3(5)$ & $13(13)$ & $5(7)$ \\
\hline Towers & $-(3)$ & $3(6)$ & $2(2)$ & - & $8(12)$ & $1(2)$ & $1(2)$ & $5(6)$ & $2(2)$ \\
\hline Lamie and lamioni & $5(6)$ & - & - & $4(4)$ & $1(1)$ & - & - & $1(1)$ & - \\
\hline Sheep pens & - & $-(2)$ & - & $2(2)$ & $1(1)$ & - & - & $-(1)$ & $1(1)$ \\
\hline Millstones & - & - & - & $1(1)$ & - & - & - & $2(2)$ & - \\
\hline Castles & - & - & - & - & $1(1)$ & - & - & - & - \\
\hline Total & $32(39)$ & $6(12)$ & $7(7)$ & $32(36)$ & $35(43)$ & $21(26)$ & $11(18)$ & $32(34)$ & $24(29)$ \\
\hline
\end{tabular}

The values in round brackets refer to the buildings on the IGM map before the overlapping process with the CTR map.

In the study area, the territory of Conversano has the highest percentage of minor buildings: 35 buildings, equal to $17.5 \%$. In the countryside of Acquaviva delle Fonti, Casamassima, and Polignano a Mare, there are 32 buildings (16\%). The remaining 34.5\% is distributed among Rutigliano with 24 buildings (12\%), Mola di Bari with 21 units (10.5\%), Noicattaro with 11 structures (5.5\%), Bitritto with 7 units $(3.5 \%)$, and Adelfia with 6 constructions (3\%). Within the single municipal areas, the distribution of buildings is not homogeneous. It has been shown that in Acquaviva delle Fonti, Bitritto, and Casamassima, buildings are spread evenly, while in Adelfia, Conversano, Mola di Bari, Noicattaro, Polignano a Mare and Rutigliano the structures are concentrated in some areas.

Figure 1 shows the prevailing land uses and the minor buildings in the LAG SEB. It is clear that there are mainly four types of agricultural crops: vineyards, orchards, olive groves and arable lands. The coastal areas of Mola di Bari and Polignano a Mare, seem to be covered almost totally by vineyards and horticultural crops, wrongly reported as arable lands also on the basis of preliminary knowledge. To finish, in this zone there are little and scattered portions of olive groves. The innermost portions of the area show three zones with a clear crop prevalence: Adelfia, Noicattaro, and Rutigliano, with vineyards; Conversano, with a clear prevalence of orchards; Bitritto, almost entirely dedicated to olive growing. As for the two more internal municipalities, Casamassima and Acquaviva delle Fonti, the situation is rather diversified, without any prevalence of a specific crop orientation. The comparison between the minor building distribution and the land use did not reveal significative connections. This evidence can be interpreted taking into account that the current land use is different from that prevailing at the time when the artifacts were built and used for their original purposes (mostly mid-1800s and early 1900s). Based on preliminary knowledge and the verifications carried out, the use of the land at that time was almost entirely intended for olive cultivation.

Figure 2 shows how the minor rural buildings are connected by the most important communication routes. Most constructions are not far from the main roads. Over $80 \%$ of them are located within a band of $1 \mathrm{~km}$ from trunk roads and country roads. Houses and villas are densified in hamlets, where they were historically used as seasonal residences for summer, such as the zone of S. Maderno belonging to the municipality of Mola di Bari, and the countryside area of Polignano a Mare. Here the buildings are served by a dense network of minor roads that constitute real residential zones. Moreover, it is evident that the density of these building types progressively increases approaching the urban centres and the main routes, whereas it decreases near the coast. Casini, instead, are widespread throughout the territory but overwhelmingly near country roads, far from urban centres, with the exception of the municipalities 
of Acquaviva and Casamassima, where the casini are evenly spread even close to the towns. Towers are positioned along linear guidelines to constitute integrated defence systems for the sighting and transmission of communications from the coast to the hinterland. This kind of communication was realized with acoustic, luminous or horse-relayed signals. For the municipality of Conversano and Polignano a Mare, other towers, arranged in arcs, completed the defensive system towards the south and the south-west, respectively. Furthermore, in the area of Acquaviva delle Fonti located in the south-east, the relationship between the roads and the building structures is less evident. Here, there are several lamie, probably because of the prevalent production destination of the area, which is also very far from the urban centre. Iazzi (sheep pens) are another construction type mainly located in areas far from urban centres. This observation is supported by the intended use of the structures, which represented seasonal or temporary shelter for livestock.

Looking at Figure 3, the progressive thinning of the houses and villas is evident, moving away from the coast towards higher areas. Many buildings belonging to these types are located within 125 meters above sea level. Instead, the towers are totally absent beyond the altitude of 225 meters above sea level. This is explained because far from the coastal area there is no longer a need for defence sighting. Cecchi (2016) showed a similar spatial distribution of towers in the Salento Area (South-east Apulia) [23]. The same evidence was reported by Errico (2020) for the historical region of Terra d'Otranto, currently comparable to the LAG Terra d'Otranto territory [24].

Figure 4 shows minor buildings and the principal karst formations. Parise et al. (2008) reported that in this zone, especially in Conversano, Mola di Bari, Polignano a Mare, and Rutigliano, the area is rich in karst dolines, caves and chasms, locally called doline, grotte, and vore [25]. These underground formations would justify the exploitation of these areas for the construction of underground structures such as oil millstones. Although in the basic cartography there are no constructions of this type, based on our preliminary knowledge, for example, we can say that in the city centre of Mola di Bari there are several underground oil mills. Therefore, this aspect was investigated. However, the relationship did not emerge. Despite the abundant confirmed presence of underground karst formations, there are not underground structures in the countryside of these areas. Dal Sasso and Caliandro (2010), explained that by the lack of residency in the rural area [26]. Here, historically, peasants tended to return to the village once their work in the countryside was finished. Therefore, it is quite logical that underground buildings are mostly located in city centres. Instead, this is not real for conterminous areas, such as the countryside of Monopoli. Here, the presence of underground oil mills is massive, because there has always been the common practice to reside in rural areas.

\section{Conclusions}

Territorial planning for the valorisation of resources must not only be aimed at the classification of buildings, but also at the connections they have with the territory. Therefore, the results were analysed regarding the relationships between the territorial features and the building heritage itself. Our findings highlighted that although all nine municipalities examined fall under the same LAG, these are very different from the point of view of territorial peculiarities and the use and enhancement of resources. The municipalities near the coast, such as Conversano, Mola di Bari, and Polignano a Mare, show more diversified potentials, as their territories include different realities (urban centres, tourist and seasonal residential areas, production areas, etc.), while the innermost municipalities are located in a context with a predominantly productive destination. To pursue integrated objectives, it is important to know the intimate relationship between rural buildings and the main territorial and environmental features. In fact, it is not possible to envisage a redevelopment of minor rural building assets without implementing, first of all, an enhancement or, at least, a correct use of territorial resources in the areas in which they are located. It must be emphasized that recovering and appropriately enhancing minor rural assets could have a positive impact in terms of both functional and landscape externalities. If, on the one hand, the recovery of a structure can be aimed at the realization within it of any activity, as long as it respects the context in which it is located, on the other hand, it cannot be denied that the redevelopment would avoid the landscape impact generated by the presence of a ruin. Finally, the results of this study could be used to integrate territorial projects aimed at the valorization of the rural territory that would be enriched by further indications concerning less historical rural constructions, from which both components would benefit. 


\section{References}

[1] Cano M., Garzón E., Sánchez-Soto P.J. Historic preservation, GIS, \& rural development: The case of Almerìa province, Spain. Appl. Geogr. 2013, 42, pp. 34-47.

[2] Ruggiero G., Sancilio C. Lettura del Territorio Attraverso un Modello di Catalogazione Della Masseria Pugliese; Quadrifoglio: Bari, Italy, 1992.

[3] Mahayuddin S.A., Zaharuddin W.A.Z.W., Harun S.N., Ismail B. Assessment of building tipology and construction method of traditional longhouse. Procedia Eng. 2017, 180, pp. 1015-1023.

[4] Picuno C., Laković I., Roubis D., Picuno P., Kapetanović A. Analysis of the Characteristics of traditional rural constructions for animal corrals in the Adriatic-Ionian area. Sustainability 2017, 9, $1441 \mathrm{p}$.

[5] Ruggiero G., Parlavecchia M., Dal Sasso P. Typological characterization and territorial distribution of traditional rural buildings in the Apulian territory (Italy). J. Cult. Herit. 2019, 39, pp. 278-287.

[6] Caruso D., Mirò A.P. Rural tourism and sustainable rural development opportunities in Apulia region (Southern Italy). In Proceedings of 9th International Scientific Conference "Business and Management 2016", Vilnius, Lithuania, 12-13 May 2016; VGTU Press: Vilnius, Lithuania, 2016.

[7] Trono A, Castronuovo V. Cultural landscape and sustainable tourism in rural areas. Case studies from the Puglia region in Southern Italy. Budapest International Conference on Tourism and Cultural Landscapes: Towards A Sustainable Approach An English language exchange of experiences Proceedings of TCL 2016 conference, INFOTA 2016, pp. 571-586.

[8] Del Lungo S., Sabia C.A., Pacella C. Landscape and cultural heritage: Best practices for planning and local development: An example from Southern Italy. Procd. Soc. Behv. 2015, 118, pp. 95-102.

[9] Picuno P. Vernacular farm buildings in landscape planning: A typological analysis in a southern Italian region. J. Agric. Eng. 2012, XLIII, e20.

[10] Amato F., Martellozzo F., Nolè G., Murgante B. Preserving cultural heritage by supporting landscape planning with quantitative predictions of soil consumption. J. Cult. Herit. 2017, 23, pp. 44-54.

[11] Fuentes J.M. Methodological bases for documenting and reusing vernacular farm architecture. J. Cult. Herit. 2009, 11, pp. 119-129.

[12] van der Vaart J.H.P. Towards a new rural landscape: Consequences of non-agricultural re-use of redundant farm buildings in Riesland. Landsc. Urban Plan. 2005, 70, pp. 143-152.

[13] Ana M-I. Tourism industry in the new Europe: trends, policies and challenges. Proceedings of the International Conference on Business Excellence. 2017, 11(1), pp. 493-503.

[14] Schiavone F, El Bilali H, Berjan S, Zheliaskov A.L. Rural tourism in Apulia region, Italy: Results of 2007-2013 rural development programme and 2020 perspectives. AGROFOR International Journal 1 (1), 2016, pp. 16-29.

[15] Tatsios K. Rural tourism as a form of cultural tourism in Apulia. Geotema 52, 2016, pp. 108-113.

[16] Cillis G., Statuto D, Picuno P. Valorisation of historical farm buildings for protecting the rural landscape. 47th Symposium "Actual Tasks on Agricultural Engineering”, 2019, Opatija, Croatia, pp. 535-544.

[17] Delibera della Giunta Regionale 16 febbraio 2015 n. 17 (Piano Paesaggistico Territoriale Regionale (PPTR) della Puglia). [online] [21.03.2021] Available at: http://paesaggio.regione.puglia.it/

[18] Council of Europe. European Landscape Convention; Council of Europe: Strasbourg, France, 2000.

[19] Ford M., Griffiths R., Watson L. The Sandford Inventory of Earth Buildings constructed using a GIS. Build. Environ. 2005, 40, pp. 964-972.

[20] Strategia di Sviluppo Locale GAL Sud Est Barese. Available at: https://www.galseb.it

[21] Ruggiero G., Dal Sasso S., Loisi R.V., Verdiani, G. Characteristics and distribution of trulli constructions into the site of community importance "Murgia of trulli". J. Agric. Eng. 2013, XLIV, pp. 87-94.

[22] Ladisa G., Todorovic M., Trisorio Liuzzi G. A GIS-based approach for desertification risk assessment in Apulia region, SE Italy. Phys. Chem. Earth 2012, 49, pp. 103-113.

[23] Cecchi A. Torri costiere - La difesa costiera nel Salento dal XVI Secolo. Elison Publishing, 2016.

[24] Errico F. Le torri "tipiche del regno" in Terra d'Otranto: caratteri morfologici e differenze costruttive. Editorial Universitat Politècnica de València, 2020. pp. 1159-1166.

[25] Parise M., Inguscio S., Marangella A. Elementi di Geomorfologia Carsica della Puglia, in Atti del $45^{\circ}$ Corso CNSS-SSI di III livello in Geomorfologia Carsica, 2008, pp. 93-118.

[26] Dal Sasso P., Caliandro L.P. The role of historical agro-industrial buildings in the study of rural territory. Landsc. Urban. Plan. 2010, 96, pp. 146-162. 